\title{
Temporal changes in gamma dose rates in the Esk Estuary, UK
}

\author{
M.D. Wood ${ }^{1}$ and D. Copplestone ${ }^{2}$ \\ ${ }^{1}$ School of Science \& the Environment, Manchester Metropolitan University, \\ Manchester, M1 5GD, UK \\ ${ }^{2}$ School of Biological \& Environmental Sciences, University of Stirling, Stirling, FK9 4LA, UK
}

\begin{abstract}
Over the last 30 years there has been a reduction in the radioactive discharges from the UK's Sellafield site. Radionuclide activity concentrations in the environment around Sellafield have declined as a result. However, routine monitoring results from the nearby Esk Estuary show a less clear trend, with fluctuations in gamma dose rate measurements being reported from year to year. A comprehensive survey $(n=576)$ of gamma dose rates in the Esk Estuary was undertaken in 2007 and the data compared to a similar survey carried out in 1989. There was a highly statistically significant decrease in the external gamma dose rates within the Esk Estuary between 1989 and 2007. The measured total gamma dose rate range in 2007 was $0.064-0.235 \mu \mathrm{Gy} \mathrm{h}^{-1}$ with a mean of $0.123 \mu \mathrm{Gy} \mathrm{h}^{-1}$. This equates to a maximum exposure of $0.200 \mu \mathrm{Sv} \mathrm{h}^{-1}$. There was no evidence of large-scale sediment redistribution under current conditions. However, there was limited evidence to suggest that part of the reason for the reduction in measured dose rates was the burial of contaminated sediment deposits by uncontaminated sediments transported by tidal processes.
\end{abstract}

\section{INTRODUCTION}

Over the last 30 years there has been a reduction in the radioactive discharges from the UK's Sellafield site and radionuclide activity concentrations in the environment around Sellafield have declined as a result [1]. However, routine monitoring results from the nearby Esk Estuary show a less clear trend. Although they reduced in line with a reduction in discharges from Sellafield, as the release of radioactive discharges levelled off, the activity concentrations at some locations in the estuary began to show fluctuations from year to year, with variation in the total gamma dose rate measured [1]. The fluctuations are thought to be due to the dynamic nature of sediment distribution in the estuary, with sediment redistribution occurring under the influence of the prevailing tidal and freshwater conditions and older, deeper, more contaminated sediments being exposed from time to time. Given the recent activity concentration and dose rate fluctuations indicated by routine monitoring, it was considered necessary to undertake a more comprehensive survey of dose rates at a range of locations in the estuary.

This paper presents the results of the comprehensive survey of gamma dose rates in the Esk Estuary, which was undertaken in 2007. The results can be compared with the findings of a similar survey undertaken in 1989 [2]. The objectives of the 2007 study were to: (i) determine the current external gamma radiation exposure from the estuary; (ii) assess temporal changes in the measured dose rates relative to the survey of the estuary that was undertaken in 1989; and (iii) use the dose rate measurements to estimate external exposure to members of the public using the estuary and compare these estimates with the annual dose limit. 


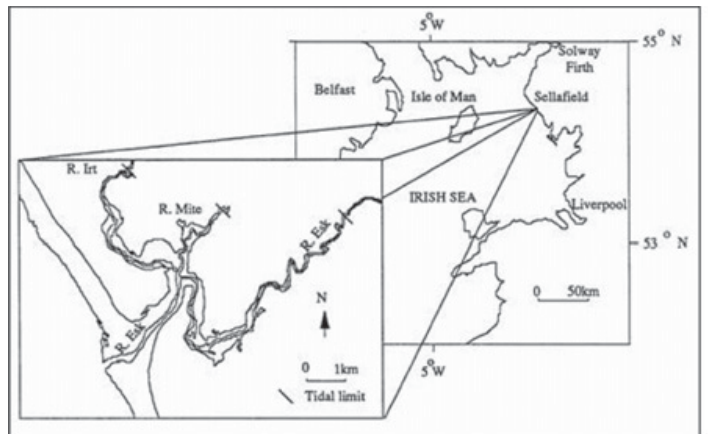

a)

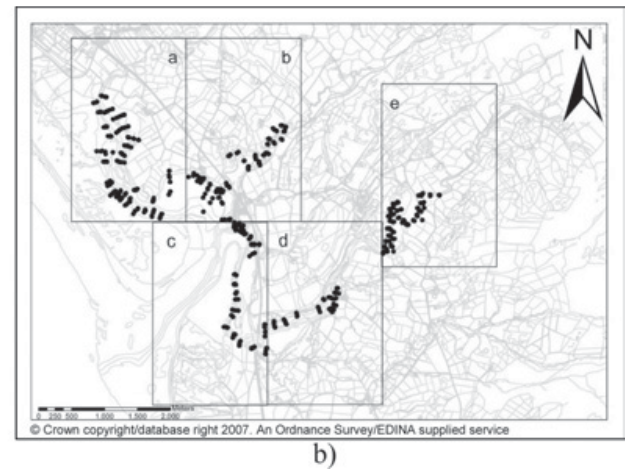

Figure 1. Maps showing (a) the location of the Esk Estuary on the west-Cumbrian coastline [3] and (b) the measurement locations for the 2007 survey and the five zones of the estuary $(\mathrm{a}-\mathrm{e})$ that were used for data comparison.

\section{METHODOLOGY}

\subsection{Field site and sampling strategy}

The Esk Estuary is located on the west-Cumbrian coastline, UK (Ordnance Survey National Grid Reference (OS NGR): SD 082 963). It is approximately $10 \mathrm{~km}$ south of the Sellafield nuclear fuel reprocessing plant and $2 \mathrm{~km}$ south of the low-level radioactive waste repository operated by Low-level Repository Ltd. The estuary is at the confluence of the rivers Irt, Mite and Esk and discharges into the Irish Sea through a narrow (approximately $400 \mathrm{~m}$ ) channel between the Drigg and Eskmeals sand dune ranges (Figure 1a).

The 1989 survey of gamma dose rates around the Esk Estuary [2] was based on an irregular grid pattern with transects perpendicular to the low-water channel. The layout of the grid was established using a $1: 25000$ scale map prior to beginning the survey. Precise measurement locations were decided at the time of measurement to ensure coverage of all major sediment facies within the estuary.

The monitoring plan for the 2007 survey was developed to enable comparison with the results from the 1989 survey. OS NGRs for the measurement locations used in the 1989 survey were entered into a Geographical Information System (GIS) software package (ArcGIS) and overlaid onto a base map of the Esk Estuary. This map was used to define the spatial extent of the survey to be undertaken in 2007 (figure 1b), with the aim of ensuring representative measurement coverage across all areas of the estuary that were included within the 1989 survey. The zones of the estuary (labelled a - e in figure 1b) correspond to: (a) Irt Estuary; (b) Mite Estuary; (c) outer Esk estuary; (d) middle Esk Estuary; and (e) inner Esk Estuary.

The 2007 survey of the estuary was undertaken over 14 days between July and August and 576 gamma dose rate measurements were made. The 1989 survey was undertaken predominantly in June and included 869 gamma dose rate measurements followed by 21 additional measurements taken in May 1990 from a small area of the River Esk, upstream of Muncaster Bridge (OS NGR: SD 113 964). The 1989 and 2007 surveys are therefore broadly comparable, both spatially and seasonally.

\subsection{In situ measurement of gamma dose rates}

Gamma dose rates in air $\left(\mu \mathrm{Gy} \mathrm{h}^{-1}\right)$ are numerically equivalent to gamma air kerma rates [4]; air kerma rate being a measure of the radiation energy that is absorbed per unit mass of air over a given time period (kerma is an acronym for kinetic energy released per unit mass). Therefore, gamma dose rates in air can be calculated from in situ measurements of gamma air kerma rates. This is the approach that was used to 
determine gamma dose rates in the Esk Estuary during the 1989 survey [2] and is the standard approach adopted for many routine monitoring and survey applications (e.g. [1]).

Measurements of gamma ray air kerma rates were made in situ using a Mini-Instruments Environmental Monitor Type 6-80 fitted with an MC71 Geiger-Muller (G-M) tube. The MC71 G-M tube was mounted vertically on a light-weight low attenuation tripod (to ensure rotational axis symmetry) and the G-M tube centre positioned at a height of $1 \mathrm{~m}( \pm 0.2 \mathrm{~m})$ above the sediment surface. This provides a field of view of approximately $8 \mathrm{~m}$ radius $\left(200 \mathrm{~m}^{2}\right)$ at $662 \mathrm{keV}$ for a typical exponential decrease in specific activity with depth [5]. A count time of 600 seconds was used, in order to ensure detection of a minimum of 700 counts [4], and the total counts per second (counts $\mathrm{s}^{-1}$ ) measured over the counting period were recorded. Measurements were not made during heavy rainfall, to reduce the likelihood of radon progeny washout influencing the results [4], or immediately after heavy rainfall when moisture in the surface sediments may attenuate the terrestrial gamma photons [6]. For the same reason, measurements immediately after exposure of sediments following tidal inundation were avoided.

\subsection{Calculation of gamma dose rates}

The total gamma dose rate measured by an instrument includes intrinsic radiation (from the material used to construct the detector), cosmic radiation (from space), and radiation from natural and anthropogenic radionuclides in the terrestrial environment. The anthropogenic component is usually the quantity of interest but, as it is not possible to measure this directly using a G-M tube, this quantity has to be calculated. To avoid confusion in the terms used to describe gamma dose rate, they are defined here as follows:

- Measured total gamma dose rate $\left(D_{I, C, N t, A}\right)$ is the sum of the dose rates from intrinsic $(I)$, cosmic $(C)$, natural terrestrial $(N t)$ and anthropogenic $(A)$ radiation. This is the measurement represented by the number of counts that the monitoring equipment records.

- Total gamma dose rate $\left(D_{C, N t, A}\right)$ is the sum of the dose rates from all sources external to the instrument. It is the measured total gamma dose rate $\left(D_{I, C, N t, A}\right)$ with the intrinsic radiation contribution subtracted.

- Terrestrial gamma dose rate $\left(D_{N t, A}\right)$ is the sum of the dose rates from terrestrial radiation, both natural and anthropogenic. It is the total gamma dose rate $\left(D_{C, N t, A}\right)$ with the cosmic radiation contribution subtracted.

- Anthropogenic gamma dose rate $\left(D_{A}\right)$ is the dose rate from anthropogenic radiation only. It is the terrestrial gamma dose rate $\left(D_{N t, A}\right)$ with the natural radiation component subtracted.

Different studies adopt different reporting approaches; some report total gamma dose rate $\left(D_{C, N t, A}\right)$ and some report terrestrial gamma dose rate $\left(D_{N t, A}\right)$. To facilitate comparison with other surveys, both quantities are reported in this paper.

The following equation was used to calculate the terrestrial gamma dose rate $\left(D_{N t, A}\right)$ :

$$
D_{N t, A}=\frac{N-P}{K}
$$

where $D_{N t, A}$ is the terrestrial gamma dose rate $\left(\mu \mathrm{Gy} \mathrm{h}^{-1}\right) ; N$ is the measured count rate (counts $\mathrm{s}^{-1}$ ); $P$ is the sum of cosmic and intrinsic detector count rates (counts $\mathrm{s}^{-1}$ ); and $K$ is the instrument-specific calibration factor for converting counts $\mathrm{s}^{-1}$ to gamma dose rate in air $\left(\mu \mathrm{Gy} \mathrm{h} \mathrm{h}^{-1}\right)$.

A typical value for $P$ is 1.00 counts $\mathrm{s}^{-1}\left(0.2\right.$ counts $\mathrm{s}^{-1}$ due to the intrinsic detector background and 0.8 counts $\mathrm{s}^{-1}$ due to the contribution of cosmic radiation $\left.[4,6]\right)$. However, these backgrounds are location and instrument specific so, to determine the appropriate value of $P$ to use for the present study, measurements were performed over Esthwaite Water (OS NGR: SD 359 969), a large water-body in Cumbria with a water depth in excess of $10 \mathrm{~m}$ and remote from surrounding high ground. Measurements were taken from a plastic boat positioned close to the middle of Esthwaite Water to ensure that the majority of counts detected would be due to the intrinsic detector background and cosmic radiation 
Table 1. Summary statistics for the estuary-level comparison of the 1989 and 2007 surveys.

\begin{tabular}{llcc}
\hline $\begin{array}{c}\text { Year of } \\
\text { survey }\end{array}$ & Statistic & $\begin{array}{c}\text { Dose rate }\left(\mu \mathbf{G y ~ h}^{-1}\right) \\
\text { Total gamma dose rate } \\
\left(D_{C, N t, A}\right)^{1}\end{array}$ & $\begin{array}{c}\text { Terrestrial gamma dose } \\
\text { rate }\left(D_{N t, A}\right)\end{array}$ \\
\hline 1989 & $n$ & 890 & 890 \\
& Mean & 0.232 & 0.183 \\
& Median & $0.178^{2}$ & $0.129^{2}$ \\
& SD & 0.135 & 0.135 \\
& Min & 0.070 & 0.021 \\
& Max & 0.608 & 0.559 \\
2007 & & & \\
& $n$ & 576 & 576 \\
& Mean & 0.123 & 0.073 \\
& Median & $0.115^{2}$ & $0.066^{2}$ \\
& SD & 0.034 & 0.034 \\
& Min & 0.064 & 0.016 \\
& Max & 0.235 & 0.186 \\
\hline
\end{tabular}

Notes: ${ }^{1}$ The 1989 total gamma dose rate data reported by [2] include the intrinsic radiation contribution; ${ }^{2}$ Highly statistically significant difference between the 1989 and 2007 median values (Mann-Whitney $U$-Test, $\mathrm{P}<0.01$ ).

contributions alone [7]. Esthwaite water is approximately $65 \mathrm{~m}$ above sea-level. Whilst it is recognised that gamma dose rate increases with altitude, the difference in the cosmic contribution to measured gamma dose rate between sea-level and $65 \mathrm{~m}$ elevation is minimal [6]. The mean $P$ value determined at Esthwaite Water was $0.059 \pm 0.004 \mu \mathrm{Gy} \mathrm{h}^{-1}(n=12)$.

To calculate total gamma dose rate $\left(D_{C, N t, A}\right)$, the assumed intrinsic detector background $(0.2$ counts $\mathrm{s}^{-1}$ ) was used in place of $P$ in the equation given above.

The 1989 survey reported measured total gamma dose rates $\left(D_{I, C, N t, A}\right)$ [2]. However, a measured value for the cosmic and intrinsic detector background at the time of the 1989 survey is also reported $\left(0.049 \pm 0.006 \mu \mathrm{Gy} \mathrm{h}^{-1}, n=2\right)$. Terrestrial gamma dose rates $\left(D_{N t, A}\right)$ were estimated in the 2007 survey, the purpose of which was to investigate the temporal change in gamma dose rates in the estuary due to changes in sediment activity concentrations. To enable direct comparison between the two surveys, $0.049 \mu \mathrm{Gy} \mathrm{h}^{-1}$ was subtracted from the measurements reported by [2] to convert the measured total gamma dose rate $\left(D_{I, C, N t, A}\right)$ to terrestrial gamma dose rate $\left(D_{N t, A}\right)$.

\subsection{Statistical analysis}

Statistical analyses were performed using SPSS 16.0 for Windows (Release 16.0.1) to determine whether there were significant differences between the 1989 and 2007 survey data for the estuary as a whole and for each zone of the estuary. In all cases, neither the raw or transformed data met the assumptions for the application of parametric statistical techniques. Therefore, the Mann-Whitney UTest (a non-parametric technique) was used to test the hypothesis that there was no significant difference between the 1989 and 2007 measurements for each data set comparison.

\section{RESULTS}

The total $\left(D_{C, N t, A}\right)$ and terrestrial $\left(D_{N t, A}\right)$ gamma dose rate data for the 1989 and 2007 surveys are summarised in Table 1. The reduction in dose rates between 1989 and 2007 was highly statistically significant (Mann-Whitney $U$-Test, $\mathrm{P}<0.01$ ). Statistically significant differences were also observed for each of the five zones of the Esk Estuary (Figure 2). Although dose rates in the estuary had declined since 1989, the areas of the estuary with elevated dose rates were broadly comparable between the 1989 and 2007 surveys (see [8] for further details). 


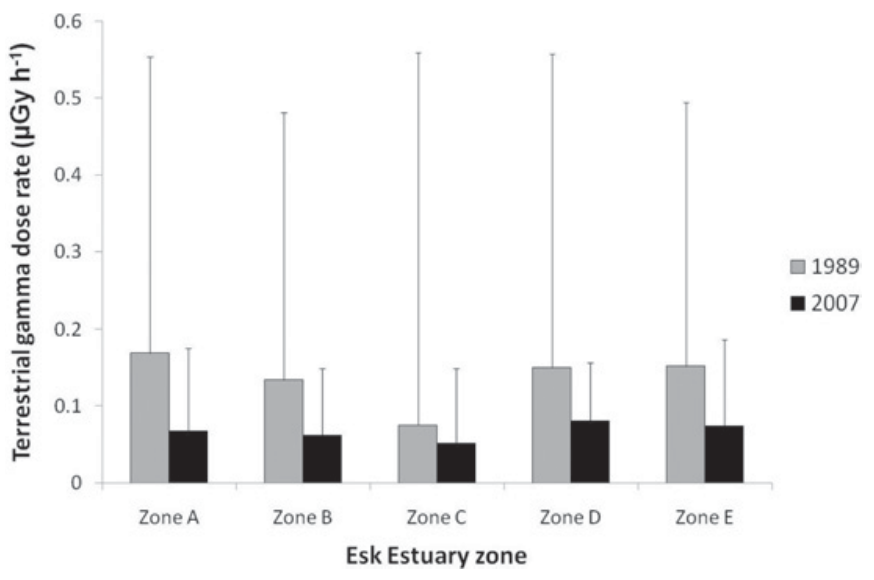

Figure 2. Change in measured gamma dose rates between 1989 and 2007 within the five zones of the Esk Estuary. Bars show median dose rates for each zone and error bars show the maximum dose rates measured.

Table 2. Summary statistics for external exposure $\left(\mu \mathrm{Svh}^{-1}\right)$ in the Esk Estuary in 1989 and 2007.

\begin{tabular}{llcc}
\hline $\begin{array}{l}\text { Year of } \\
\text { survey }\end{array}$ & Statistic & $\begin{array}{c}\text { Dose rate }\left(\mu \mathbf{S v ~ h}^{-1}\right) \\
\text { Total exposure }\end{array}$ & Terrestrial exposure \\
\hline $1989^{1}$ & $n$ & 890 & 890 \\
& Mean & 0.197 & 0.156 \\
& Median & 0.151 & 0.110 \\
& SD & 0.115 & 0.115 \\
& Min & 0.060 & 0.018 \\
& Max & 0.517 & 0.475 \\
2007 & & & 576 \\
& $n$ & 576 & 0.062 \\
& Mean & 0.105 & 0.056 \\
& Median & 0.098 & 0.029 \\
& SD & 0.029 & 0.014 \\
& Min & 0.054 & 0.158 \\
\hline
\end{tabular}

Notes: ${ }^{1}$ For the purposes of comparison, exposure values for the 1989 survey were recalculated using the 0.85 conversion factor proposed by the ICRP [9].

The calculated total and terrestrial dose rates $\left(\mu \mathrm{Gy} \mathrm{h}^{-1}\right)$ were converted to external exposure $\left(\mu \mathrm{Sv} \mathrm{h}^{-1}\right.$ ) using a Gy to $\mathrm{Sv}$ conversion coefficient of 0.85 for a rotational geometry and photon energies in the range $50 \mathrm{keV}-2 \mathrm{MeV}$ [9]. This is in agreement with the approach adopted for regulatory monitoring in the United Kingdom (e.g. [1]). Summary statistics for external exposure are presented in Table 2.

The maximum total external exposure in the estuary had reduced from $0.517 \mu \mathrm{Sv} \mathrm{h}^{-1}$ in 1989 to $0.200 \mu \mathrm{Sv} \mathrm{h}^{-1}$ in 2007 . Thus, if exposure was solely from external radiation in the estuary, a member of the public would have to be present at the maximum exposure location (in the inner Esk Estuary) for 5,006 hours ( 0.57 years) to reach the $1 \mathrm{mSv}$ annual dose limit. Although other exposure pathways are not considered, it is evident that this level of occupancy at the location of maximum external exposure is highly unlikely; the actual maximum annual occupancy in the estuary (combining recreational and occupational occupancies) having been determined through habits survey as 424 hours [10]. Also, the above calculation is based on a 'worst case' total dose rate, which includes cosmic, anthropogenic and natural terrestrial radioactivity contributions, whereas the $1 \mathrm{mSv}$ annual dose limit is a regulatory limit for exposure from anthropogenic sources. 


\section{DISCUSSION}

The reduction in terrestrial dose rates $\left(D_{N t, A}\right)$, and therefore external exposure, throughout the estuary, is likely to be due to the combined influence of decreasing radionuclide discharges from the Sellafield site, radioactive decay of Chernobyl-derived ${ }^{137} \mathrm{Cs}\left(\mathrm{t}_{1 / 2}=30\right.$ years), and burial of contaminated sediment as indicated by the sub-surface ${ }^{137} \mathrm{Cs}$ and ${ }^{241} \mathrm{Am}$ activity concentration maxima that have been reported for the estuary [8]. This burial of contaminated sediments would increase the attenuation of gamma photons by the overlying sediment, especially lower energy gamma photons, and reduce the measured external gamma dose rates as a result.

Given that the areas of the estuary with elevated dose rates were broadly comparable between the 1989 and 2007 surveys, there is no evidence of significant large-scale redistribution of contaminated sediment within the estuary. However, as tidal regimes alter under the influence of climate change and sea-level rise, increasing wave energies may begin to expose (and potentially remobilise) some of these contaminated sediments. Given the extent of radionuclide contamination of the Esk estuary it would be prudent to more fully assess the current radionuclide inventory within the estuarine sediments and, in conjunction with available modelling predictions for sea-level changes over various time horizons, assess the potential for remobilisation of this accumulated inventory and the resultant risks to people and the environment.

\section{CONCLUSION}

This study has demonstrated a highly statistically significant decrease in the external gamma dose rates within the Esk Estuary between 1989 and 2007. The measured total gamma dose rate $\left(D_{I, C, N t, A}\right)$ range in 2007 was $0.064-0.235 \mu \mathrm{Gy} \mathrm{h}^{-1}$ with a mean of $0.123 \mu \mathrm{Gy} \mathrm{h}^{-1}$. This equates to a maximum exposure of $0.200 \mu \mathrm{Sv} \mathrm{h}^{-1}$.

There is no evidence of large-scale sediment redistribution under current conditions. However, there is limited evidence to suggest that part of the reason for the reduction in measured dose rates is the burial of contaminated sediment deposits by uncontaminated sediments transported by tidal processes. Given the likely influence of future sea-level rise on tide action within the estuary, consideration should be given to assessing the potential risks associated with large-scale exposure and remobilisation of these contaminated sediments.

\section{Acknowledgments}

This work was funded by the Environment Agency of England and Wales.

\section{References}

[1] RIFE 1996 - 2008. Radioactivity in Food in the Environment (RIFE-1 - RIFE 13). Available from: http://www.cefas.co.uk/publications/scientific-series/radioactivity-in-foodand-the-environment (rife). aspx

[2] Emptage, M., Kelly, M. Gamma dose rates in the Esk Estuary. (University of Lancaster, Lancaster, 1990).

[3] Kelly, M., Emptage, M. Distribution of radioactivity in the Esk estuary and its relationship to sedimentary processes. (University of Lancaster, Lancaster, 1991).

[4] HMIP, Routine measurement of gamma ray air kerma rate in the environment - Technical Guidance Note (Monitoring) M5. (Her Majesty's Inspectorate of Pollution, London, 1995).

[5] Tyler, A.N., Sanderson, D.C.W., Scott, E.M., Allyson, J.D., J Environ Radioact 33 (1996) 213235. 
[6] Thompson, I.M.G., Botter-Jensen, L., Deme, S., Pernicka, F., Saez-Vergara, J.C., Technical recommendations on measurements of external environmental gamma radiation doses - Radiation Protection 106 (European Commission, Luxembourg, 1999).

[7] Ambrosi, P., Metrologia 46 (2009) S99-S111.

[8] Wood MD, Hall PJ, Wittrick S, Copplestone D, Leah RT, Survey of gamma dose rates in air around the Esk Estuary (Environment Agency, Bristol, 2011)

[9] ICRP, Ann ICRP 26 (1996).

[10] Doddington, T., Camplin, W.C., Caldwell, P., Investigation of external radiation exposure pathways in the Eastern Irish Sea, 1989. (Ministry of Agriculture, Fisheries and Food (MAFF), Lowerstoft, 1990). 